\title{
Primary anterior parietal wall abscess due to Salmonella Typhi
}

\section{Authors}

Kamlesh Thakur, MD ${ }^{1}$

Gagandeep Singh ${ }^{2}$

Poonam Gupta ${ }^{2}$

Smriti Chauhan ${ }^{2}$

Subhash Chand Jaryal, $\mathrm{MD}^{3}$

${ }^{1}$ Associate Professor, DRRPGMC, Tanda,

Himachal Pradesh, India

${ }^{2}$ Postgraduate Student,

Indira Gandhi Medical

College, Shimla, Himachal

Pradesh, India

${ }^{3}$ Assistant Professor, Indira Gandhi Medical College, Shimla, Himachal Pradesh,

\section{TO THE EDITOR}

Enteric fever is endemic in most of the developing regions, especially the Indian subcontinent. Salmonella Typhi (S. Typhi) bacteremia is known to be associated with extra-intestinal disease. It is capable of forming abscesses in various organs, such as spleen, subcutaneous tissue and skin. ${ }^{1,2}$ The pathogenesis of abscess formation is not well established. Salmonella spp. can, though rarely, cause soft tissue infections at sites of local trauma.

Our patient was a 38-year-old newly diagnosed diabetic female admitted to the surgical ward with chief complaints of pain, swelling in the left hypochondrium region and fever for two weeks. Local examination of abdomen revealed a single, $8 \times 6 \mathrm{~cm}$ globular mass with smooth surface, and normal overlying skin in left hypochondrium. Clinical impression of parietal wall abscess was made. These findings were further confirmed on ultrasonography (USG) and CT scan (Figure 1). Incidentally, a single gall stone was also found on USG. Incision and drainage (I/D) was performed on two occasions, at two weeks interval. Pus obtained was processed as per standard protocols. ${ }^{4}$ The first I/D yielded only sterile pus, while the second showed growth of non lactose fermenting colonies on MacConkey agar, with typical biochemical reactions of $S$. Typhi. Serotyping with specific polyvalent (poly O), monovalent (O9) and Vi antisera confirmed the diagnosis. The organism was sensitive to cotrimoxazole, gentamicin, ciprofloxacin, ceftazidime, ceftriaxone, and resistant to ampicillin, nalidixic acid and chloramphenicol.

Figure 1: Abdomen CT Scan (Plain) shows a hypodense lesion $(7.5 \times 4.3 \mathrm{~cm})$ localized to subcutaneous plane on left side of anterior abdominal wall.
Submitted on: 02/06/2009 Approved on: 06/25/2009

Correspondence to: Dr. Gagandeep Singh Cedar Villa, Nav Bahar Himachal Pradesh, India.

Pin Code: 171002

Phone (Mobile):

+91-987-8370024

E-mail: drgagandeep@

gmail.com

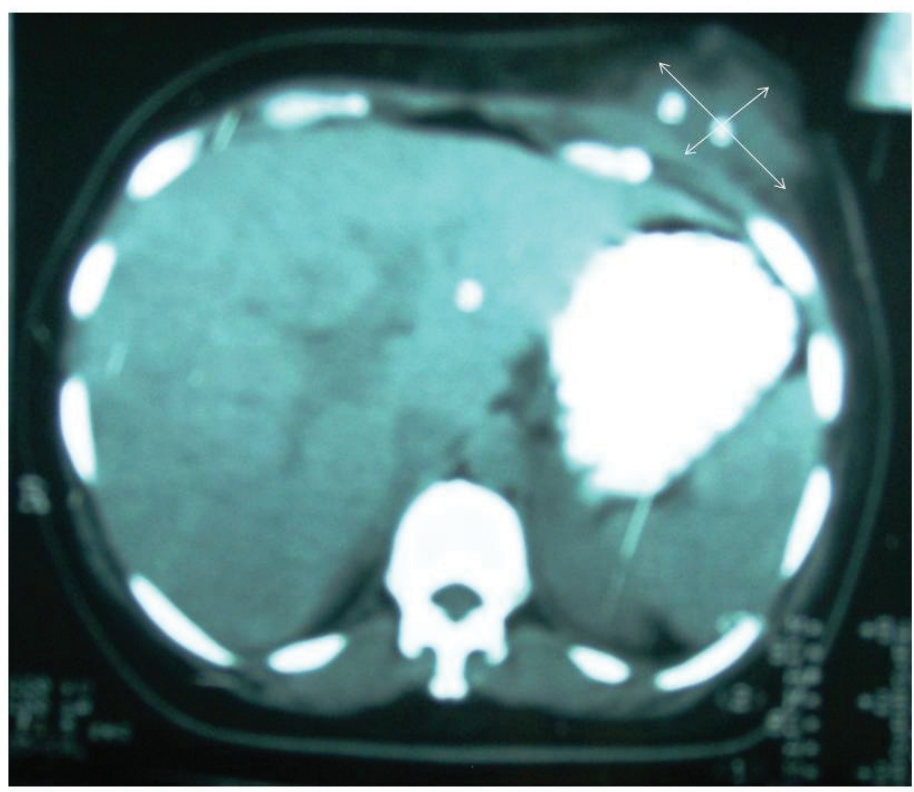


The present case documents an unusual finding of left sided anterior parietal wall abscess caused by serotype Typhi not associated with detectable bacteremia. This can be explained by a possibility that our patient had a very short, transient bacteremia, which probably was not picked up by the physicians. Blood and urine culture prior to antibiotic therapy were sterile. Stool culture was not performed prior to antibiotic therapy, as salmonella infection or its carrier state was never suspected. But the existence of a carrier state could not be ruled out in the present case, because our patient was a female with cholelithiasis, residing in an endemic area. Consequently, she may have been harbouring subclinical infection. Widal test was also negative. The host susceptibility to salmonella infection is known to be augmented by lowered immunity due to predisposing factors, such as diabetes mellitus. The asymptomatic serotype Typhi carrier state is commonly reported in female patients with gall stones. The infected bile may lead to chronic carriage and serve as a reservoir for future metastatic disease. ${ }^{5}$ The first incision and drainage presumably acted as a triggering factor. Only few cases of subcutaneous and cutaneous abscesses caused by serotype Typhi have been reported. ${ }^{3,6,7}$

In addition, the isolate was sensitive to ciprofloxacin though resistant to nalidixic acid. Nalidixic acid resistant $S$. Typhi (NARST) strains either need to be treated with higher doses of ciprofloxacin (10 mg/Kg twice a day) or antibiotics, like third generation cephalosporins. Our patient responded well to higher doses of ciprofloxacin therapy for a period of six weeks. In conclusion, although $S$. Typhi infection is endemic in many of the developing countries, one should remember that these infections can have varied presentations, thereby being a dilemma to the microbiologist and the treating physician.

[Braz J Infect Dis 2010;14(4):328-329]@Elsevier Editora Ltda.

\section{REFERENCES}

1. Ciraj AM, Reetika D, Bhat GK, Pai CG, Shivananda PG. Hepatic abscess caused by Salmonella Typhi. J Assoc Physicians India 2001; 49:1021-2.

2. Sarma PS, Narula J. Multiple Salmonella Typhi subcutaneous abscesses in a sickle cell anaemia patient. J Assoc Physicians India 1996; 44:563-4.

3. Raghunath R, Ashok AC, Sridaran D, Indumathi VA, Belwadi MR. A case of injection abscess due to Salmonella Typhi. Indian J Med Microbiol 2003; 21:59-60.

4. Collee JG, Fraser AG, Marmion BP, Simmons A. Mackie And McCartney Practical Medical Microbiology. London: Churchill Livingstone, 1996.
5. Lai CW, Chan RC, Cheng AF, Sung JY, Leung JW. Common bile duct stones: a cause of chronic salmonellosis. Am J Gastroenterol 1992; 87:1198-9.

6. Shakespeare WA, Davie D, Tonnerre C, Rubin MA, Strong M, Petti CA. Nalidixic acid-resistant Salmonella enterica serotype Typhi presenting as a primary psoas abscess: case report and review of the literature. J Clin Microbiol 2005; 43:996-8.

7. Marzano AV, Mercogliano M, Borghi A, Facchetti M, Caputo R. Cutaneous infection caused by Salmonella Typhi. J Eur Acad Dermatol Venereol 2003; 17:575-7. 